\title{
KIAORA - the emerging construction of a bicultural professional supervision model
}

\section{Lisa King}

Lisa King - Ngāti Kahu ki Whangaroa me Ngāti Kohua.

\begin{abstract}
The KIAORA model is the culmination of responding to the challenge of constructing a personal model of professional supervision within a bicultural worldview. Mātauranga Māori and kaupapa Māori is the tūrangawaewae for construction of a personal model of professional supervision for a Tangata Whenua social work practitioner seeking to transform the Aotearoa New Zealand professional supervision space.
\end{abstract}

\section{Introduction}

The purpose of this article is to articulate the emerging construction of my personal model of professional supervision. In 2010 I engaged in a process that challenged me to deconstruct my supervision practices and engage in the reconstruction and naming of a personal model of professional bicultural supervision in harmony with a Māori worldview. Deconstruction of my supervision practice enabled me to hold my practice up to scrutiny against my espoused philosophies, values, principles, desires and stance as a Tangata Whenua practitioner. I have researched Māori ontological, epistemological and cosmological informed ways of knowing, being and doing. This emerging model is my commitment to the grounding of my practice in Te Ao Māori, where kaupapa Māori, matauranga Māori and tikanga Māori is the tūrangawaewae - foundation for the reconstruction of my professional supervision practice.

\section{Background}

The question, 'Are you a social worker who is Māori or a Māori social worker?' was posed to me as a new social worker more than 20 years ago. The question raises issues of identity, and opens one to the possibility that depending how you answer the question, has implications for how you develop your practice and how you perceive the world. I identify myself in the social work world as a wahine Māori by whakapapa, committed to working in ways which strengthen the whakapapa weave that has been frayed from the impact of colonisation, imperialist agendas, and the ongoing development and imposition of those agendas to the detriment of Māori.

Most important to my identity as a Tangata Whenua practitioner is the desire to ensure that my social work with Māori is founded on a Māori worldview and the philosophies and practices that stem from this worldview. This is a commitment to the achievement of oranga in all its manifestations for whānau, hapū and iwi through the realisation of tino 
rangatiratanga and mana motuhake. No less than was guaranteed Māori under the Treaty of Waitangi. No less than is our birthright. No less than the actualisation of the purpose of social work which, 'promotes social change, problem solving in human relationships and the empowerment and liberation of people to enhance well-being ...' (International Federation of Social Workers (IFSW) and the International Association of Schools of Social Work (IASSW), 2002).

My experience, and a critique of the social work profession by many indigenous social workers, is that social work is, 'essentially a profession grounded in a Eurocentric worldview and value system' (Weaver, 2008, p. 71). It follows, therefore, that supervision generally in this country is also grounded in a Eurocentric/western worldview and value system.

I view supervision as an influential and essential component of the totality known as social work. Thus the same philosophical, ethical and cultural issues apply equally to supervision as to social work (Ohia, 1986, p. 1).

Gray, Coates \& Yellow Bird (2008) challenge the imposition and relevancy of western models and interventions into local contexts and promote authentisation. To;

... generate knowledge and practice from the ground up ... whereby local culture is used as a primary source of knowledge and practice development, social work practice can become culturally appropriate, relevant and authentic. Authentization may lead to a rethinking of what is really universal in social work (2008, p.5).

Ruwhiu (1995) encouraged Māori social workers to access Tangata Whenua philosophies and experiences for the range of conceptual frameworks that could be ordered into theoretical frameworks. He told us 'our answers were in our own stories' (p. 24), reinforcing there was no need to justify and legitimate our experiences of being Tangata Whenua using Western Eurocentric paradigms. Within the social work profession, Tangata Whenua kaimahi Bradley, Jacob \& Bradley (1999), Eruera (2005), Davis in Thomas \& Davis (2005), Mataira (1985), Walsh-Tapiata \& Webster (2004) and Webber-Dreadon (1999) have written about social work supervision models, approaches and frameworks founded in a Māori worldview where the cultural constructs birthed in a Māori world continue to have relevance in the development of Tangata Whenua social work practice and supervision.

\section{Mai i Te Kore ki Te Pō ki te Ao Mārama e}

Tohua ngā whakatipuranga ki te inu i te puna o te mātauranga.

Kia hora ai te whakaruruhau o te ora ki runga ki te iwi.

Kia kaha, kia toa, kia manawanui.

Show the young how to drink from the spring of knowledge.

So the sheltering mantle of wellbeing may spread over the nation.

Be strong, be courageous, be resolute (author unknown).

Māori efforts to seek knowledge, to organise it and to learn from it are not new. The sources of our engaging with knowledge and theory-building are our whakapapa kōrero; our creation stories, pūrākau, myths and legends, whakatauki speak of our metaphysical, ontological, epistemological and cosmological beginnings. They tell of how we came to be, of 'the universe as process ... a world comprised of a series of interconnected realms separated by aeons of 
time from which there eventually emerged the Natural World' (Marsden, 2003, p.31). The separation of Rangi and Papa, the stories of their children - our gods, their domains and the names of their progeny connect and guide us in our relationships with our world and each other. The story of ngā kete o te wānanga is a story of how mātauranga/knowledge came to the earth and provides guidance on how we engage with mātauranga and with all that abounds; 'myth and legend were deliberate constructs employed by the ancient seers and sages to encapsulate and condense into easily assimilable forms their view of the World, of ultimate reality ...' (Marsden, 2003, p. 56).

A Māori worldview, the explanations we give for what we see, know, hear, feel, think and do, gives coherence to our lives and is the weaving together of the various parts to make the whole. Worldviews as defined by Marsden are, '...the central systemisation of conceptions of reality to which members of its culture assent and from which stems their value system' (2003, p. 56). Marsden (2003) describes a Māori worldview that consists of at least three realms; that are integrated, unified and form the holistic approach of the Māori. Te Korekore is the realm of potential, Te Pō the realm of becoming and Te Ao Mārama, the realm of being. This model of the universe, 'i Te Kore, ki Te Pō, ki Te Ao Mārama' - out of the nothingness, into the night, into the world of light' is the creative process of manifestation (Shirres, 1997). I am conscious of the power of both the seen and unseen, kei tua o te arai, and that this influence is ever present and available. It will be about how connected I am.

This model of creation is also an analogy for the creation/construction of my supervision model. It was seeded in the realm of potential through my supervision experiences as both a supervisee and supervisor; it has traversed the realm of becoming as I have come to make meaning of the weave of my supervision experiences, and by me naming it and placing it before others it comes into being. Tīhei mauri ora!

According to Smith, 'Māori knowledge represents the body of knowledge which, in today's society, can be extended, alongside that of existing Western knowledge' (1999, p. 173). Royal (2002) also supports the active engagement and extension of Māori knowledge identifying the following prerequisites:

a) the need for indigenous peoples to articulate our interpretations of our worldviews, both traditional and contemporary, and for us to create our own indigenous epistemologies and theories of knowledge,

b) the need for indigenous peoples to be in control of the processes by which indigenous knowledge is taught, preserved and created,

c) the need for indigenous peoples to embrace an ethos of creativity, to explore and research traditional knowledge bases inspired and motivated by a creativity that will revivify these knowledge bases and traditions in the contemporary and modern world (2002, p. 11)

Kaupapa Māori theories and frameworks have arisen as a response to the aforementioned prerequisites and as a direct challenge by Māori to the taken-for-granted ways knowledge is created and legitimised that use a positivist science paradigm to shape conceptions and expectations of objective, valid, truthful and worthy research. Kaupapa Māori theory is a way of opening the theoretical space to Māori theorising sourced in our worldviews, our philosophies;

...it is a way of abstracting that knowledge, reflecting on it, engaging with it, taking it for granted sometimes, making assumptions based on it, and at times critically engaging in the way it has and is being constructed (Nepe, cited in Smith, 1999, p. 188). 


\section{Nature of a bicultural context}

The context in which I construct supervision is heavily influenced by the many people I have had the privilege to work alongside. I have been providing external supervision for more than 13 years. Not all of those I have supervised have been social workers, some have been kaiāwhina, whānau workers, counsellors, administrators, youth workers, caregivers and managers, but all work with whānau Māori. Most supervisees have been Māori, some have been Pasifika and Pākehā, and most have been women. I provide both group supervision and individual supervision. I also engage in peer supervision with a group of wāhine Māori and individual supervision with a wāhine Pākehā.

The theoretical and practical challenges of developing indigenous social work practice is an acknowledgement that, 'mainstream social work is, at its core, a Western cultural creation and to recognise that 'good' and effective social work practice demands that we make culture explicit in thinking and practice' (Gray \& Coates, 2010, p. 6). The deconstruction of supervision practice and engagement in biculturalism's 'ideals of social justice and recognition of uniqueness and difference' (Pohatu, 2003, p. 1-2) through the assertion of the equal contribution of Tangata Whenua/Indigenous ways of knowing, seeks to transform the Aotearoa New Zealand professional supervision space.

The Treaty of Waitangi, biculturalism and the politics of indigeneity are used by Māori to assert our place and space in this country as tāngata whenua and to ensure that we are not relegated to minority status within our own country; 'without a strong commitment to Māori self-determination and an honest reworking of colonial institutions biculturalism ends up as little more than a revamped multiculturalism with a Polynesian twang' (Fleras and Spoonley, cited in Johnson, 2008, p. 37). Bicultural supervision situates the personal and the professional within the political and cultural. It presents an opportunity to proclaim a critical approach to engaging in the professionalisation of supervision from a Māori worldview. According to Pohatu (2003) the underpinning philosophies of Māori worldviews remind us of our cultural purpose and obligations and 'affirm the obligations placed with each generation to undertake contracts to ensuing generations' (p. 6)

Therefore my construction of an emerging model of professional supervision obliges me to ensure that my personal supervision model is, as previously stated, grounded in a Māori worldview, this is part of my birthright, obligation and purpose. This is a kaitiaki (guardian - 'taking care of') function that I can serve as an external supervisor to ensure that Māori worldviews and those principles and practices, those tikanga that stem from such a view have pre-eminence in my supervision practice.

My bicultural model of professional supervision does not deny the contributions of other worldviews to supervision as appropriate. The usefulness and potential inclusion of aspects of non-Māori supervision models, tools and skills as part of my kete is part of the potential of a bicultural model of supervision. The proviso is that it must be congruent with my Te Ao Māori worldview and that I be alert - kia mataara of any 'colonising' tendencies in my supervision practice. The expectation of the model proposed here is that I be ever vigilant in its commitment to progress change towards realisation of tino rangatiratanga, mana motuhake and oranga in the lives of whānau Māori. 
Wisdom is a thing of the heart.

It has its own thought processes.

It is here that knowledge is integrated, for this is the centre of one's being (Maori Marsden, 2003, p. 1)

\section{KIAORA professional supervision model}

Given that this is the foundation for the model of my supervision practice, I then had to explore from my experiences of supervision those aspects that appeared to me to be fundamental to supervision, and then to name my model. I considered Kai Ora as the name for supervision based on the whakatauki, 'ko te kai a te rangatira he kōrero - kōrero is the food of chiefs', and an acknowledgement to a roopu I provided external supervision to. I understood for them that Kai-tahi, coming together for peer supervision, meant also the sharing of kai. I understand the sharing of kai as symbolic and part of our tikanga in respect to whakanoa - to free from restriction.

However, I chose the name KIAORA; the natural way of greeting each other here in Aotearoa is also a cheer to life, to wellness, which supervision must contribute towards as must our practice with those we work with. This introduction to my KIAORA model of supervision uses each letter to represent a particular principle and acknowledges that each of the strands can be 'unwoven' for a deeper understanding of their contribution to the weave of this model.

\section{Kōrerorero}

'Te kai o te rangatira' is about respectful reflexive supervision discussions in which a Kaupapa Māori analysis is applied to supervision take. Korerorero respectfully recognises our responsibility to those we speak about in supervision, that we uphold te mana o te kupu me te tangata. Kōrerorero is the discussions and agreement to the kawa of supervision about the purpose and process of supervision and seeking agreement to the working alliance and supervision agreement.

\section{Practice example}

When I meet potential supervisees for the fi time, our fi hui is primarily about whakawhanaungatanga, including connecting to see what their purpose is and why they are interested in supervision with me. What are the connections that bring us together? Most prospective supervisees come because of connections and referrals from others whom I have either provided supervision to or because they are colleagues who know that this is part of my mahi. It is also in the initial discussions, if not already known to the prospective supervisee, that I declare my bias; a Māori worldview is my pre-eminent worldview and I am interested mainly in providing supervision for kaimahi Māori and those who work with Māori from this space. Discussions about the kawa and tikanga of supervision also include an acknowledgement that we will work together on nga take the supervisee brings into the session and it is their perspective of the take that is presented.

\section{Ira Atua - Ira Tāngata}

This is about our creative potential and the acknowledgement of Te Ao Wairua in all our interactions e.g. through karakia, within the supervision session and within practice. Ira Atua - Ira Tangata is an acknowledgement of the human and divine sides of ourselves connected through whakapapa. This recognition requires the protection of whakapapa and our 
responsibility to work in ways that respect and strengthen the whakapapa weave of those we work with. This is about whanaungatanga which guides and obligates the quality and nature of our relationships.

\section{Practice example}

Most often I am providing supervision to kaimahi Māori and there are some assumptions I can make about beginning and/or ending our sessions with karakia. Karakia for me in this space is a karanga - it is the acknowledgement of and a call for protection, support, guidance and healing when appropriate from kaitiaki, atua and tupuna. It is a way of anchoring the space for our supervision session, bringing focus and intention to the discussions. I have witnessed kaimahi exhale audibly during and post the karakia, to thank me for it as they have become tau - settled in themselves, and in the acknowledgement that they are not alone in their journey, there is assistance available from kei tua o te arai - the 'unseen' world.

At the first supervision session with a wahine Māori I had known for many years, I asked whether there was a way she wished to start the session. She acknowledged her comfort with me and was ready to go into the korero on the take. Then she stopped herself and asked that we start with karakia as she was going to be talking about other people in her take. She acknowledged their whakapapa and wanted to call for guidance to uphold practice principles of whanaungatanga, tika, aroha and pono in our kōrero and her mahi. I thank her for the reminder about being deliberate in the interaction.

\section{Ako}

Ako is about critically engaging with Mātauranga Māori, Kaupapa Māori and non-Māori knowledge for their transformative possibilities for practice. It recognises the reciprocal nature of the relationship between the supervisor and supervisee as both teachers and learners (see also example above). Ako also means that when we kōrero about the whanau we are working with we are open to their 'knowing' and the learning they bring us, and we consider how we can reciprocate and share our 'knowing' with them.

\section{Practice example}

I provided roopu supervision for Māori and Pasifika social workers and support workers in a Māori community organisation. As part of roopu supervision kawa we agreed that after our karakia and whakawhānaungatanga the sessions would be led by the take they brought into our kōrero. Part of my role was to seek agreement that the take were relevant to their roopu supervision session and to facilitate the sharing of kōrero so that all could contribute their questions, understandings and possible solutions to the resolution of take.

A kuia in the roopu raised a dilemma for her in providing services for Pasifika peoples; she wondered whether she was culturally appropriate. We explored a particular case in which the kuia was working with a Samoan man. One of the strengths of the roopu was the two Pasifika social workers who contributed to discussions from their cultural worldviews (the diversity that exists across Pasifika peoples and within each of their nations was acknowledged). We discussed the whanaungatanga relationship between Tangata Whenua and Tangata o te Moana nui a Kiwa; whether as part of establishing the working relationship the kuia had discussed the service being kaupapa Māori (which she had) and her wondering about her suitability as a kuia Māori working with him (which she had not). 
There were several other issues we explored as a roopu in regards to the kōrero, including that none of them had sought cultural supervision for working with Pasifi families. I raised for their consideration how as Māori we demand culturally responsive services of tauiwi, and that we surely must apply the same standard to our own practice with Pasifi peoples and other ethnicities. I am not talking about working with Pākeha as this is part of what being bicultural for Māori already means; we know the dominant worldview and its norms. One of the outcomes of the session was for the roopu to raise with their manager the possibility of cultural consultation with a Pasifi person on a case-by-case basis as required to increase their understanding of working cross-culturally with Pasifi peoples.

\section{Oranga}

Oranga is acknowledged as a continual journey seeking balance and harmony in its expression in our lives. The supervision interaction actively engages in healing and wellbeing discussions and encourages this as an outcome of interactions with whanau we work with. Mauri Ora - the Divine Spark of Life is alert and active in its expression of wellbeing.

\section{Practice example}

I will call her 'wahine toa', and she came into our session holding mamae. When I say mamae I am saying that in the course of our kōrero it became apparent that her mana had been demeaned by actions of her colleagues and her manager who were threatened by her competence. Her translation of those actions to her practice had served to undermine her confidence so that she began doubting she could take her full self into interactions with them.

Part of my role in respect to oranga was to explore with her previous positive work situations where she experienced herself as empowered and respected, to explore the differences primarily between those people and places, for the purposes of guiding her back to herself, the wise kuia. As a result of our kōrero she reaffirmed her reasons for being where she was, she accepted where she was and had no expectation that her work team provide what she had experienced elsewhere as the people, wā and wāhi were different. Her confidence in herself was restored and she had a strategy which allowed her to return to her mahi and maintain her own mana and wellbeing.

Not long after our kōrero she was enticed into a role as part of an innovative initiative that had the potential to transform whānau Māori realities, where her particular strengths were valued and where she could take herself into the interactions as a mana wahine.

\section{Rangatiratanga}

This is about mahi rangatira - professional practice which upholds the mana of those we have the privilege of working with. For Māori, best practice is experienced as an expression of tino rangatiratanga. Professional practice is about an ongoing commitment to the development of our practice, the profession and ourselves as ethical professionals.

\section{Practice examples}

In my role as supervisor this may be as simple as asking when a supervisee is talking about a young person they are working with - have you asked him what his whānau think of how he is living his life currently and how involved in your mahi with him are they? How are you working with his whānau even though for your organisation he is the client? How can 
you work in ways that support you to strengthen those ties that may have been frayed from past actions on his and/or their part? It might also be asking someone why this person has not been referred to kaimahi Māori and or an Iwi/Māori service. And when they respond that the person does not want to work with Māori, my challenge is how then can you work in ways with this whānau to reintroduce them and invite them to participate in Te Ao Māori, given what we know about internalised racism. How do you work in ways that encourage the strengthening of the whakapapa weave?

\section{Āhurutanga}

Ảhurutanga is about a protected and safe supervision space for refl discovery, recovery and continued journeying for kaimahi. This is how I uphold my kaitiakitanga obligations to take care of, to uphold values and ethical patterns, to guide, support and correct as appropriate in the supervision space (Pohatu, 2003).

Issues of 'employer - employee fit' is a thread that at times weaves itself into my experience as an external supervisor. To me, this exploration is a legitimate benefit of external supervision as a place for supervisees to exhale about employer and/or collegial relationships as they impact on their mahi and wellbeing. Āhurutanga in this sense provides the space to explore perspectives and opportunties to reframe, problem solve and reconcile the tensions that are part of the work experience. This is part of 'hohou-te-rongo' - reconciling our take so that we are at peace with ourselves and the choices we make.

\section{Practice examples}

I had one supervisee for whom the 'employer-employee fit' take was a prominent theme over several sessions. It was negatively impacting on her work and her wellbeing. The resolution of it for her meant that she found other mahi and resigned.

Another example of āhurutanga from my own supervision 'herstory' with a tāne Māori supervisor. I used my external supervision space to explore my dilemma of leaving an employer and a kaupapa I was passionate about because, in part, my issue of 'fit'. Supervision enabled me to explore in safety how to leave one space well in order to move to the next space, to determine what it is I wanted to leave as my 'koha' to the service and how to negotiate this change whereby I honoured myself, my relationships and my mahi. In respect to 'hohou-te-rongo' I left supervision with an exit strategy, reconciled and at peace with my decisions. I have stayed involved in the kaupapa and mahi of that organisation.

\section{Conclusion}

The KIAORA Supervision model is firmly grounded in Te Ao Māori; Kōrerorero, Ira Atua Ira Tangata, Ako, Oranga, Rangatiratanga and Āhurutanga as supervision pou are in fertile ground. The integrated holistic nature of Te Ao Māori means that any examination into its various aspects shows their whanaungatanga relationship to each other and enhances the understanding of its application to practice. The interconnectedness of Te Ao Māori means we have a common natural language that allows us to interact with each other whilst respecting our diversity, and the beauty of the whole is enhanced by the contribution of the many. It means we can also adapt from each other in that I have adapted from my understanding and the knowing of others. 
This article has been an oppportunity for me to reflect again about the purposes and practices of my supervision and how as a Tangata Whenua supervision practitioner I can contribute to the transformative possibilities of supervision that resonate with Te Ao Māori. I have unfurled my supervision takapou whāriki KIAORA - sharing how I have made sense of ancient wisdom woven into my current context - KIAORA.

I am thankful to all my supervisees and supervisors for their influence in my development. I dedicate this KIAORA model to my first Tangata Whenua external supervisor, Paraire Huata; and the first two kuia I had the privilege of supervising some years ago, Whaea Margaret Hickey and Whaea Phyllis Davis. He mihi tēnei kia koutou kua para i te huarahi mōku, kia tutuki pai ōku nei mahi. Kāore e mutu aku mihi maioha kia koe Paraire. He mihi hoki ki te tokorua, ko Whaea Phyllis rāua ko Whaea Makere, ahakoa kua ngaro kōrua i te kitenga kanohi, kei roto tonu kōrua i tōku ngākau, nei rā te mihi.

\section{References}

Bradley, J., Jacob, E., \& Bradley, R. (1999). Supervision: Reflection on culturally safe supervision or why Bill Gates makes more money then we do. Te Komako III Social Work Review, XI (4), 3-6.

Eruera, M. (2005). He korero korari (Master's thesis). Palmerston North: Massey University.

Gray, M., \& Coates, J. (2008). Introduction. In M. Gray, J. Coates, \& M. Yellow Bird (Eds.), Indigenous social work around the world (p. 5). Surrey: Ashgate.

Johnson, J. (2008). Indigeneity's challenges to white settler-state: Creating a third space for dynamic citizenship. Alternatives, 33, 29-52.

Marsden, M. (2003). The woven universe: Selected writings of Rev. Maori Marsden (C. R. Te Ahukaramu, Ed.). Masterton: The Estate of Rev. Maori Marsden.

Mataira, P. (1985). A bi-cultural model of social work and social work supervision. Palmerston North: Massey University.

Ohia, R. (1986). Ethnic-sensitive supervision in social work. Palmerston North: Massey University.

Pohatu, T. (2003). Maori world-views: Source of innovative social work choices. Te Wananga O Aotearoa.

Royal, T. (2002). Indigenous worldviews: A comparative study. Te Wananga o Raukawa.

Ruwhiu, L. (1995). Home fires burn so brightly with theoretical flames. Social Work Review, 21-24.

Shirres, M. P. (1997). Te Tangata: The human person. Newton: Accent Publications.

Smith, L. (1999). Decolonizing methodologies: Research and indigenous peoples. London \& Dunedin: Zed Books Ltd \& University of Otago.

Thomas, C., \& Davis, S. (2005). Bicultural strengths-based supervision. In M. Nash, R. Munford, \& K. O'Donoghue (Eds.), Social work theories in action (pp. 189-204). London: Jessica Kingsley.

Walsh-Tapiata, W., \& Webster, J. (2004). Do you have a supervision plan? Aotearoa New Zealand Social Work Review, 15-19.

Weaver, H. (2008). Indigenous social work in United States: Reflection on Indian tacos, Trojan Horses and canoes filled with Indian revolutionaries. In M. Gray, J. Coates, \& M. Yellow Bird (Eds.), Indigenous social work around the world (pp. 71-82). Surrey: Ashgate.

Webber-Dreadon, E. (1999). He taonga mo o matou tipuna: An indigenous approach to social work supervision. Te Komako III Social work review, XI (4), 7-10. 